\title{
Muslims and evolution: a study of Pakistani physicians in the United States
}

\author{
Donald Everhart ${ }^{1 *}$ and Salman Hameed ${ }^{2}$
}

\begin{abstract}
This study investigated the views of Pakistani-American medical doctors regarding biological evolution. We used a mixed-methods approach, chiefly consisting of a short interview that presented evolution in the contexts of microbial, animal, and human evolution; evolution's acceptability or unacceptability to Muslims; and evolution's relevance to medicine. The participants were 23 doctors attending a convention in the United States. Fourteen participants accepted evolution, three rejected evolution, and six held other views. While a majority of participants indicated that they accepted evolution, a slightly smaller plurality accepted human evolution. A majority of participants, including some who did not wholly accept or reject evolution, thought that one could mutually accept evolution and also believe in Allah. Nearly every participant, including two who rejected evolution, thought that evolution was relevant to medicine. We find that participants assigned a plurality of meanings to the theory that depended on interactions between a participant's perception of religion, science, medicine, and a host of other cultural influences. This study is the first of a collection of studies carried out by the authors, who collected data with the same instrument in five other countries with significant populations of Muslim doctors and medical students.
\end{abstract}

Keywords: Muslims, Culture, Evolution and religion, Evolution and medicine, Evolution acceptance, Evolution rejection

\section{Background}

The theory of evolution pervades the public discourse in ways that are matched by few other scientific theories. In the United States, Darwin's theory provokes debate on matters of religion, politics, and education even while forming the cornerstone of modern biological thought. While there are many reports on American attitudes regarding evolution, these reports most frequently emphasize the attitudes of majority religious and cultural groups. This study explores the views of Pakistani physicians living in the US, a segment of the educated Muslim elite.

Polls conducted over the last couple of decades have consistently shown that less than half of all American adults accept the idea that humans evolved naturally, over time, from prior species (Newport 2012; Gallup Inc 2012; Masci 2009). Those same polls demonstrate that large segments of American adults agree that the Earth

\footnotetext{
* Correspondence: deverhart@ucsd.edu

1 Department of Sociology, University of California, San Diego, 401 Social Science Building, 9500 Gilman Drive. La Jolla, CA 92093-0533, USA Full list of author information is available at the end of the article
}

was created sometime within the last 10,000 years. In accompaniment to these attitudes, there have been ongoing battles in various school boards, state legislatures, and, occasionally, even in the US Supreme Court, over the inclusion of religiously-motivated alternative theories to evolution in the school curricula (Miller et al. 2006; Numbers 2006).

While opposition to the acceptance of biological evolution in the US is vocal and highly organized, the controversies over evolution are now also visible in other parts of the world - from South Korea (Kim \& Nehm 2011) to the Netherlands (Koning 2006), the United Kingdom (Allgaier 2010) and throughout the European Union (Curry 2009, Blancke 2011). Recently, researchers have also begun to investigate the attitudes Muslims hold toward the theory of evolution, and if they share the opinions of other religious populations (BouJaoude et al. 2011a; BouJaoude et al. 2011b; Asghar \& Alters 2007; Edis 2007). Some of these early studies reveal a widespread rejection of the theory of evolution in countries like Turkey, Egypt and Pakistan, with the 
acceptance level even below that of the US (Hameed 2008). Some of these opinion polls have known shortcomings. For example, some in the Muslim world associate 'Darwin's theory of evolution' primarily with atheism and not necessarily with the idea of biological evolution. This association has even permeated scholarly literature on the subject, as a study of Muslim religiosity used evolution acceptance as an indicator of low religiosity (Hassan 2007).

While researchers have begun to investigate the attitudes Muslims, particularly Muslim biology students and educators, hold regarding evolution, this study is the first to focus on the views of Muslim doctors. Because this study was created with the views of Muslim doctors in mind, we chose our subjects at one of the largest gatherings of such doctors in the US - the annual Pakistani-American medical conference. For several decades, significant numbers of doctors educated within Pakistan have immigrated to Western countries to practice medicine (Gish and Godfrey 1979; Zaidi 1987). As a consequence many Pakistani-American doctors are well organized and form one of the largest groups of immigrant physicians in the US.

Since our focus is on doctors who were educated in Pakistan, it is important to note the place of the theory of evolution within the Pakistani national biology curriculum. Medical students first get exposed to biological evolution in high school biology classes, where the presentation of evolution within the curriculum and textbooks is comparable to that within many Western science curricula (Punjab Textbook Board 2003; Asghar \& Alters 2007). Nevertheless, a recent study shows that medical students in Pakistan have low knowledge of evolutionary theory as well as low acceptance of the theory (Yousuf et al. 2011). At the same time, almost two-third of the students surveyed agreed that evolutionary medicine, if taught, would improve medical research.

In this study, we explore three key ingredients that constitute attitudes towards evolution among our study population. The first consists of a sliding scale of evolution acceptance, which describes our participants' views on microbial, animal, and human evolution. The second inquires about evolution in relation to aspects of Islamic beliefs and the religiosity of individual participants. The third presents participants' considerations of evolution's relevance to medicine. We find that through these three different contexts, many Muslim doctors in this community consider the theory of evolution to have several significant meanings. Our results are part of an ongoing study of Muslim physicians and medical students in countries across the world.

\section{Methods}

Data for this project were collected using an interview protocol developed specifically for this study. The interview protocol employs mixed qualitative and quantitative methods, as described in Tashakkori and Teddlie (2002) and consists of nine sections, designed to last between ten and thirty minutes per participant.

The instrument underwent several pilot studies, after which it was revised into its present form. The pilot studies were conducted with Muslim doctors of various countries of origin, including Pakistan, who currently reside and practice medicine in the US. The pilot studies took place between 2008 and 2010.

This interview protocol was developed based on of previous studies that have measured attitudes towards evolution and religiosity. For example, on the subject of understanding concepts of evolution, we drew from the Measure of Acceptance of the Theory of Evolution (Rutledge \& Warden 1999) and the survey employed by Shtulman (2006). We adapted some of the religiosity indicators from the Pew Forum on Religion and Public Life (Ruby \& Smith, 2007; The Pew Forum on Religion and Public Life, 2008) and from the sociological study on Muslim religiosity by Hassan (2007). In addition, we followed the works of Evans \& Evans (2010) and Brem et al. (2003) to explore other social factors that might also have significant influences on attitudes towards evolution.

We also asked participants if they had heard of Harun Yahya, Richard Dawkins, and Charles Darwin. Harun Yahya is the pen name of Turkish creationist Adnan Oktar. His organization has been responsible for distributing Atlas of Creation, unsolicited, to various public schools in France and anthropology and biology departments in the US (Riexinger 2002; Enserink 2007). Richard Dawkins is a prominent evolutionary biologist who has written multiple books about evolution and is also a vocal proponent of atheism. Even though Darwin's name is familiar to most people in the West, we wanted to see if it was also commonly recognizable among Muslims. We plan to compare the responses of participants in this study to those of other populations in a future study.

The last section of the instrument consisted of a semantic differential (Tashakkori and Teddlie 2002). Participants were given a series of polarized terms or concepts that were related to perceptions of evolution and were asked to provide their instantaneous response. The use of this semantic differential is meant to be largely comparative and does not feature into the analysis presented in this paper. A separate, forthcoming study will analyze participants' responses to this section.

The data presented in this paper were collected on 1 to 2 July 2010 at the largest annual gathering of Pakistani doctors in the US. One of the authors (blinded for the manuscript) recruited participants by approaching them directly or with the help of another participant. Interviews were conducted individually and in English. Prior to the 
start of each interview, participants completed an informed consent form and a brief written demographic questionnaire. Participants were reminded that the interview was voluntary and anonymous, and were assured that their anonymity would be protected. Twenty-three physicians of various ages, sexes, specialties, and backgrounds agreed to participate.

Overall, our questions and methodology were designed to elicit a progressive depth of response over the course of an individual interview and were approved by the Hampshire College Institutional Review Board.

\section{Results}

We interviewed 23 participants at a conference of Pakistani physicians in the US. In response to the question, 'Do you accept or reject the theory of (biological) evolution', fourteen replied affirmatively and three rejected the theory (Figure 1). The responses of six additional participants were coded as 'other.' This coding of 'other' indicates that they either did not completely accept or reject evolution, or that they were unsure of how to express their views. An example of this response includes a participant who was 'not entirely convinced' but was 'impressed with the concept [of evolution].' Another participant said that he did not accept the theory as stated, but would 'offer an amendment that there is a creative design and this is the mechanism by which species change.'

Throughout the rest of the paper, we have used the responses coded in Figure 1 as the primary reference point.

\section{Sliding scale of evolution acceptance}

In order to further explore the level of acceptance of evolution, we sequentially asked the participants about microbial and animal evolution and if humans were a product of evolution from prior species (Figure 2). The majority of the participants thought that evolution was possible in all three instances. However, the level of

\section{Do you accept or reject the theory of evolution?}

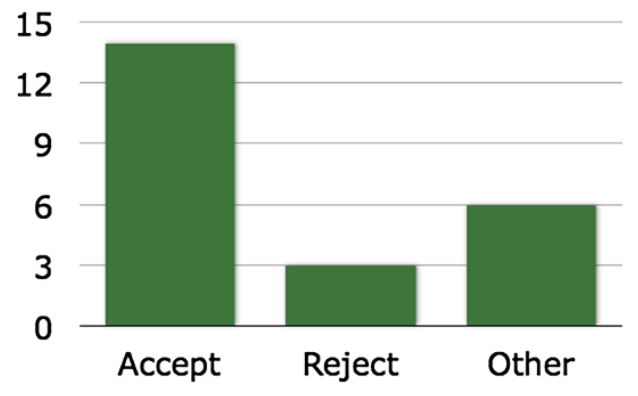

Figure 1 Study participants' acceptance or rejection of the theory of evolution.
Do you think that microbial evolution is possible?

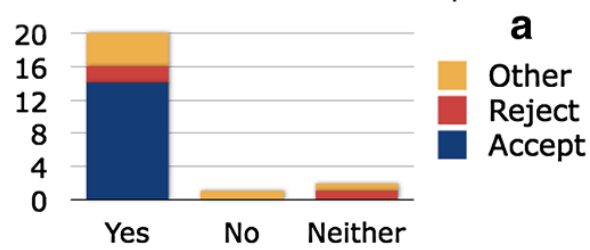

Is animal evolution possible?

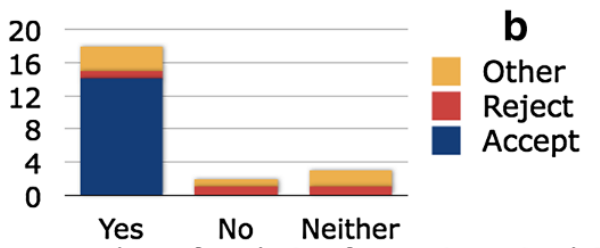

Are humans a product of evolution from prior animals?

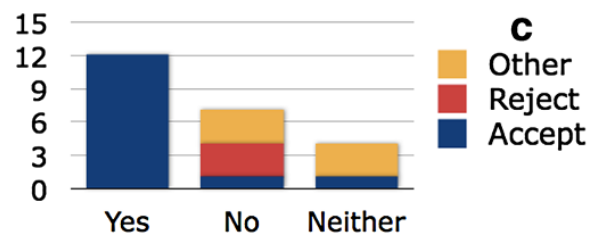

Figure 2 On the possibility of microbial (2a), animal (2b), and human $(2 \mathrm{c})$ evolution, as categorized by responses in Figure 1.

acceptance of human evolution, perhaps not too surprisingly, is relatively lower.

When looking at the acceptance of microbial evolution (Figure 2a), we found that only one participant (subject \#13) in our entire sample rejected microbial evolution. It was his opinion that species could change only in limited ways, from 'A... to A+'. This was coherent with his view that antibacterial resistance was a process in which bacteria become stronger, but do not become new species. In contrast, two of the three participants who rejected evolution nonetheless thought that microbial evolution was possible. One of these participants (subject \#6) even accepted the idea of animal evolution, but stopped short of extending his acceptance to human evolution.

Two other participants thought microbial evolution was neither possible nor impossible. One of those participants (subject \#21) chose to answer all three questions about microbial, animal, and human evolution with a simple 'probably.' On the other hand, one other participant (subject \#22) was unsure of microbial and animal evolution ('I'm not aware of anything. May be it has happened, you know, like in the jungle. . who knows what is happening!'), but was clear about her rejection of human evolution (Figures $2 \mathrm{~b}$ and $2 \mathrm{c}$ ). She was one of the participants who responded negatively to the question of evolution in Figure 1.

Every participant who rejected evolution in Figure 1 also rejected the idea that humans have evolved from prior species. Only one participant who responded positively in Figure 1 rejected human evolution (subject \#11). Three 
participants (subjects \#12, 13, 16) who were classified as 'other' were also clear about rejecting human evolution. For example, one participant (subject \#16) who was 'impressed but not convinced' by the concept of evolution nevertheless denied the possibility of human evolution.

Three of the six participants who were classified as 'other' in Figure 1 are also unclear about human evolution. However, they display a broad range for their reasons. For example, one of the participants (subject \#4) expressed that he was torn when it came to human evolution saying 'I guess anything is possible, but it's just, you get confused, when it becomes - you know - beliefs. It is hard to, there are a lot of things that you are not really sure, but you kind of have to believe in it.' Another participant (subject \#21) seemed non-committal and responded 'probably' to microbial, animal and human evolution.

As a method of checking the consistency of participants' views in regard to the extent of evolution, participants were also asked if they thought that humans shared genes with apes and bacteria. A majority of the participants who were asked this question thought that humans did share genes with apes and bacteria, including one participant who responded negatively in Figure 1. That participant (subject \#9) thought that humans shared genes with apes and bacteria, although he said his religious beliefs prevented him from accepting that humans evolved from prior species. Participants who were classified as 'other' in Figure 1 did not see a link between human genes and the genes of apes and bacteria. Only one such participant (subject \#13) said, 'part of the genes are I think being shared" although he did not think microbial evolution was possible, let alone that humans evolved from prior species.

Taking into account the predominance of young earth creationism in the US, participants were also asked a question about the age of the earth. Every participant thought that the earth was at least millions of years old. Nineteen out of the twenty-three participants correctly estimated the earth to be billions of years old. This result displays a notable lack of influence from young earth creationists in the US and elsewhere.

Overall, most participants in this study said that they accepted the theory of evolution. There was some erosion from the number of participants who thought microbial evolution was possible to the number who thought humans had evolved from prior animals. Nonetheless, a plurality of participants did think that humans had so evolved, including twelve participants who had responded positively in Figure 1. This positive response to human evolution displays the depth with which some participants accepted evolution.

\section{Evolution and Islam}

Religion plays a dominant role in most Muslim-majority countries. Pakistan is no exception. A recent report found that $94 \%$ of Pakistanis said that religion was 'very important in their lives', exceeding the rates of many Middle Eastern and North African countries (The Pew Forum on Religion and Public Life 2012, 40). Since most of the participants were trained in Pakistan and had spent a large fraction of their formative years in Pakistan, we wanted to see how they related evolution to their religious beliefs. Specifically, we investigated the impact of their religious views on their acceptance or rejection of evolution. The US polling organization, Gallup, has been collecting data on the range of theistic, naturalistic, and creationist perspectives on evolution in the US with the same statements since 1982 (Gallup Inc 2012). We slightly modified their question by using 'Allah' instead of 'God' and eliminating young earth creationism. We posed the following question (Figure 3):

Which of the following four statements is closest to your view?

A: all species, including humans, have evolved over millions of years, but Allah guided the process.

B: all species, including humans, have evolved over millions of years, and Allah played no part.

C: Allah created humans, but all other species have evolved over millions of years.

D: Allah created humans and all other species in the form they exist today.

These categories broadly correspond, respectively, to theistic evolution, naturalistic evolution, the special creation of humans, and the special creation of all species.

Ten of our participants identified with the statement corresponding to theistic evolution. Eight of those participants also accepted evolution, one rejected evolution, and one was categorized at 'other' in Figure 1.

The participant who rejected evolution but chose this option said that, 'Everything has evolved but Allah created, Allah made them evolve'. As with the participant who accepted evolution but chose option ' $\mathrm{D}$ ', this

Which of the following four statements is closest to your view?

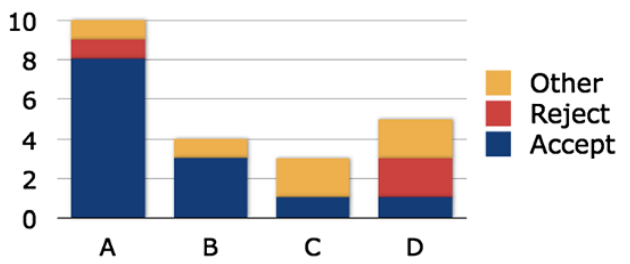

Figure 3 Identifications with four statements incorporating evolution and religion, as categorized by responses in Figure 1. 
participant distinguished between his perception of the theory of evolution and his interpretation that was acceptable to his Islamic views.

The second largest category proved to be option 'D', corresponding to a creationist view. Five participants chose this view, consisting of two participants who rejected evolution, two with other views, and one who accepted evolution. As discussed above, the participant who accepted evolution and chose option ' $\mathrm{D}$ ' expressed her choice as being between 'A' and 'D', indicating a desire for a statement that expressed a strongly theistic account of evolution. A similar theistic drive was apparent in two of the three participants who chose option ' $\mathrm{C}$ ', which expressed the view that evolution is a real process but that humans were created specially by Allah. The participant who chose option ' $C$ ' but also accepted evolution did not elaborate on his choice.

Out of the four participants who chose option 'B', corresponding to naturalistic evolution, three accepted evolution and one had 'no view.' All three participants who both responded positively in Figure 1 and also chose option 'B' in Figure 3 were emphatic about their acceptance of evolution. Notably, the one other participant who chose 'B' was the same participant who responded with a uniformly laconic 'probably' to the questions displayed in Figure 2 (participant \#21).

In addition to this multiple-choice identification, participants were asked if they thought one could simultaneously accept evolution and also believe in Allah (Figure 4). All but two participants who accepted evolution also thought that one could do so and believe in Allah. One of those two participants stressed the incompatibility of religion with science. 'If you think purely in terms of science and how the life came about,' he said, '. . .then I think you don't have to believe in God'. (subject \#23) Another participant who also identified with naturalistic evolution offered the contrasting opinion that, 'You can [believe in God], if you want to... just for your heart'. However, most participants who accepted evolution held views that bound religion and evolution more closely together. For example, a neurologist said that in my theory [evolution is] how I believe

Do you think one can accept evolution and also believe in Allah?

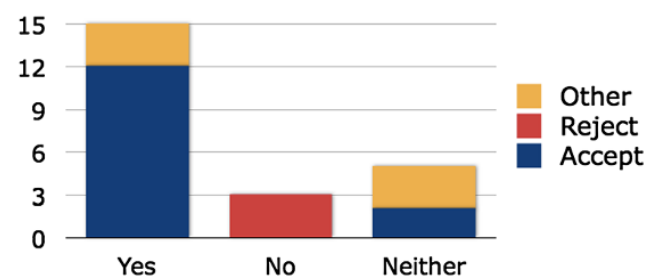

Figure 4 Whether one can accept evolution and also believe in Allah, as categorized by responses in Figure 1 . that God created the universe millions and billions of years ago and that is true if you look at Islam'.

Participants who rejected evolution expressed the opposite opinion. All three thought that you could not believe in Allah and also accept evolution. When asked, one participant who rejected evolution said, 'I think Allah is the creator of everything, so um, no'. Another participant echoed this firm line, saying she did not think that acceptance of evolution was compatible with belief in Allah, 'because... you read the Qu'ran, according to that we were created'.

Participants who had views other than acceptance or rejection sometimes expressed the idea that acceptance of evolution might be difficult to reconcile with belief in Allah, but none ruled it out completely. Two such participants thought that it was definitely possible to accept the theory and also believe in Allah. In a demonstration of how casual such acceptance can be, one of those participants said, 'I'm doing it, right?'

As can be seen from these responses, most of the participants regarded evolution and Islam as being mutually acceptable. To further explore participants' religiosity, we asked about the frequency with which they prayed and also the degree to which they considered themselves to be religious.

Figure 5a displays some variability among participants' self-reported religious behavior. Four participants who accepted evolution prayed five times a day, as did all three participants who rejected evolution. Three other participants who had other attitudes towards evolution also prayed five times a day. Several participants who prayed five times a day were emphatic about doing so, as in the

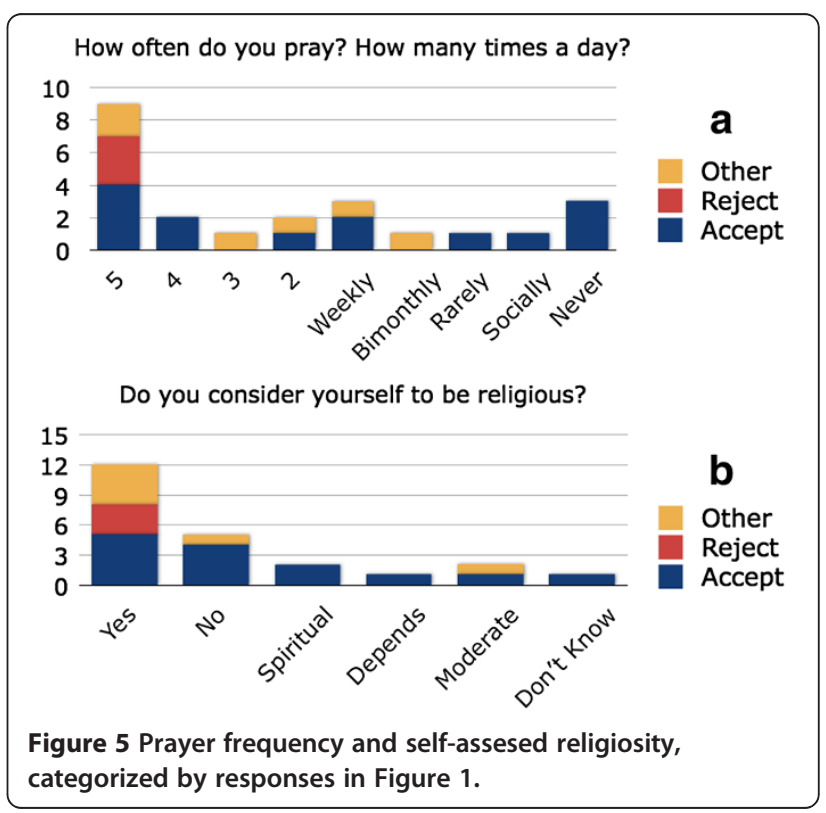


case of the participant who said, 'What do you mean?! You can't be [Muslim], without prayer!' (subject \#22)

Participants who accepted evolution exhibited the widest range in the amount of times they said they prayed each day, week, or month. One participant who accepted evolution and prayed four to five times a day said that she frequently had difficulty performing the fajr salat, or morning prayer, because of her late night schedule. Even though she sometimes performed the morning prayer late, she considered the effort she put towards performing all five daily prayers to be of significant personal importance (subject \#14). Another participant who accepted evolution did not share her attitude towards prayer. He said that while prayer facilitated friendly connections, it was unimportant as a personal or devotional activity. Jokingly, that participant said that he prayed 'only when my friends are around me' (subject \#23).

The regularity with which a participant said that they prayed was related to that participant's self-identified religiosity (Figure 5b). Just as participants who accepted evolution exhibited more variance in their prayer frequency compared to the other two groups, those same participants also showed more variation in their selfassessed religiosity. Participants who accepted evolution were more likely to respond that they were not religious, or that they were spiritual, moderately religious, or didn't know. One such participant who said that he was 'somewhat religious' explained his view further. 'Maybe I believe', he said, 'but maybe I don't practice... Let's bring that in there... And there are lots of people like this'. (subject \#18)

Every participant who rejected evolution considered himself or herself to be religious. This correlated to the strong importance all three of those participants assigned to performing the five daily prayers. Similarly, most of the participants who accepted evolution and also straightforwardly considered themselves to be religious prayed five times a day. The main exception to this trend were participants who had other views, the majority of whom considered themselves to be religious yet estimated that they prayed fewer than five times a day.

Four of the five participants who said that they did not consider themselves to be religious said they prayed rarely or not at all. All four of those participants also identified with the option for naturalistic evolution displayed as option 'B' in Figure 3. These participants were very open about their distance from religion, with two such participants (subjects \#8, \#23) identifying as atheists.

In sum, when biological evolution and Islam are held up together, most participants considered the two to be hypothetically compatible. Furthermore, the plurality of participants actually identified with statements that expressed belief in a process of evolution that was guided by
Allah. Participants who did not fit neatly with the positions held by their peers highlight the complexity of positions held by the group as a whole. This included participants who held a positive view of evolution but also felt strongly that Allah created rather than guided life and also participants who held worldviews that emphasized naturalistic evolution and largely excluded religious beliefs and behaviors.

\section{Evolution and medicine}

With the increasing importance of evolutionary medicine, we wanted to investigate if our interview participants saw a connection between evolution and medicine. Indeed, most participants asserted that the theory of evolution played a role in modern medicine (Figure 6). Unsurprisingly, this included every participant who accepted evolution. Significantly, however, two participants who rejected evolution as well as four participants who had other views also considered the theory to be relevant to medicine. Several participants provided examples, including two participants who considered the theory of evolution to be essential to the study of stem cells.

Of the three participants who did not consider evolution to be relevant to medicine, only one was sure that evolution did not play any role in modern medicine. According to that participant, "the human body is so fascinating that uh, there has to be a... super being, which has created this thing'. (subject \#13) That participant was a psychiatrist who thought there could be positive changes in health between generations, but no evolution of the kind 'from a monkey to a human being'. He was not alone in this assessment. One other participant who rejected evolution and thought that the applicability of evolution came in 'certain aspects of it but not wholly, like, you cannot say that human are evoluted from monkeys, no' (subject \#22).

Those two dissenting participants were in a distinct minority when it came to the subject of evolution's relevance to medicine. That there were so few participants who shared their opinion hints that many participants held a professional evaluation of evolution distinct from their other evaluations of the theory. Even participants who felt religious discomfort with evolution nonetheless

Do you think the theory of evolution plays a role in modern medicine?

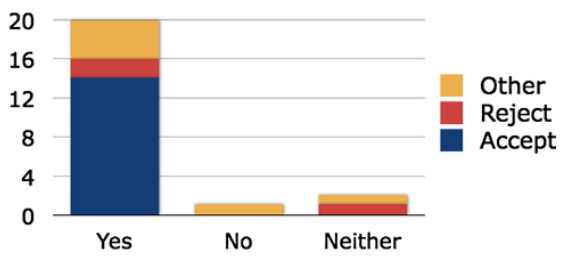

Figure 6 The relevance of evolution to medicine, categorized by responses in Figure 1. 
expressed the opinion that the theory was of medical value.

This professional evaluation of the instrumental value of evolution seemed to be divorced from those same participants' religiously-inflected perspective. This capability to bracket one meaning of the theory of evolution from another was further substantiated by the remarks of those participants who did not agree that evolution was relevant to medicine. As described above, those participants continued to express their disapproval of the evolution of humans from prior species even when asked to consider the theory from a professional perspective. In so doing, those participants were in the clear minority among their peers. Most of the participants in this study considered the theory of evolution to have subtly different meanings when held up against religion, medicine, or different levels of biota.

\section{Demographics}

We found that participants' sex, age, and time spent in the US had no correlation with the acceptance or rejection of evolution (Figure 7).

\section{Discussion}

The aim of this study was to explore the way a segment of the educated Muslim elite, Pakistani physicians living in the US, view biological evolution. While most of the participants in our study accepted evolution, we found a deep

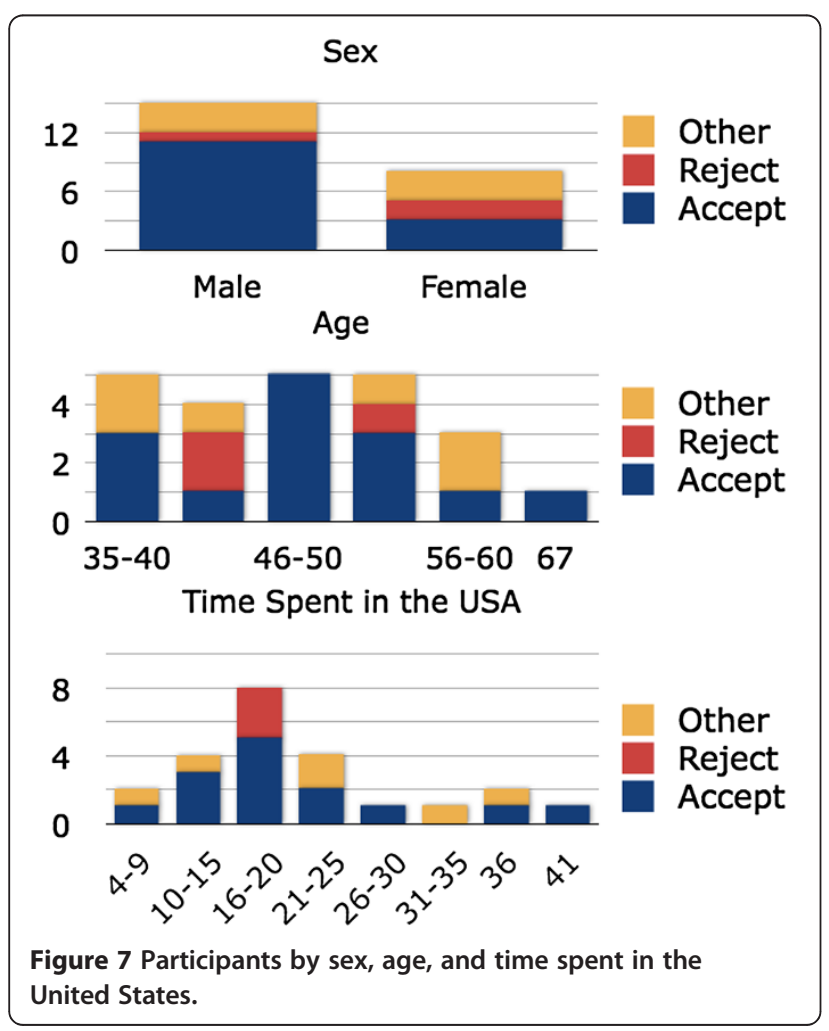

level of negotiation between cultural contexts (often, deep religious values) and science. Some participants in our study, indeed, held the theory to a more univocal meaning based on the powerful influence of a particular context, but most invested their concept of 'evolution' with multiple meanings.

This is not unusual. The work of Geertz (1973) and Knorr (2007) argues that many of us interact regularly with multiple cultures (or cultural elements). This interaction both brings meaning to concepts and also causes those concepts to have a proliferation of meanings.

Indeed, most participants took the meaning of the theory of evolution to be fluid. This fluidity of meaning allowed the participants to evaluate their concept of evolution in relation to the contexts provided by the interviewer (for example, religion, practical applications, etc.). This is not to say that the participants in this study did not properly understand the meaning of evolution, but rather that evolution is a theory that has outgrown a univocal epistemological meaning. It is not the case that our participants displayed 'hybrid epistemologies' (Kitcher 2008), but rather that the theory of evolution may possess meanings outside of the realm of epistemology.

Furthermore, the dynamic interaction of cultural influences presented here challenges future investigators to demonstrate how multiple categories of thought regarding evolution and religion interact with each other. A mere demarcation between those participants who hold naturalistic, theistic or creationist perspectives on evolution does not capture crucial elements of the cultural influence of theory. While surveys of acceptance and rejection rates remain useful, we cannot gain from these reports an understanding of the qualities that motivate people to accept or reject evolution. Indeed, the results of this study demonstrate ways in which people have different ideas of what it means to accept or reject the theory: the perception of evolution is bound up in the shifting meanings assigned to the theory by interactions between that participant's perspectives on religion, science, medicine, and a host of other cultural influences.

Strikingly, most participants (even most of those who rejected evolution!) thought that the theory of evolution was relevant to medicine. When the theory is presented as having a potentially instrumental use, individuals who consider evolution to have very different meanings may agree on its utility. This interpretation of our results places the findings of previous studies that explore medical professionals' perspectives on evolution in a different light. For example, in a study of Scottish medical students, Downie (2004) came to the conclusion that acceptance of evolution and its perceived value to medicine are positively linked. In a follow-up study, Southcott and Downie (2012) found that 'the importance of a belief precluding evolution' was the most 
crucial motivation for a student's rejection of evolution (Southcott \& Downie 2012). We are of the opinion that these claims show how people's attitudes towards evolution change when different meanings of the theory are given different weights. We have only a handful of physicians in this study who reject evolution, but we aim to investigate this further with a larger sample of Muslim physicians and medical students.

\section{Conclusion}

We have presented results of a study of 23 physicians of Pakistani origin residing in the US. We find that a majority of these doctors not only accept biological evolution, but also the idea that humans have evolved from prior species. At the same time, we find that there is a dynamic and fluid interaction between their scientific views and their own religious and cultural context. Almost all of these doctors (20 out of 23) saw the relevance of evolution to medicine, including those who rejected evolution. Similarly, we did not see any correlation between the acceptance of evolution and religiosity, but all the doctors who rejected evolution were religious.

\section{Competing interests}

The authors declare that they have no competing interests.

\section{Acknowledgments}

This study was funded by grant ID 0925982 under the National Science Foundation's Science, Technology, and Society (STS) program. The authors would like to thank Dr. Anila Asghar, Dr. Laura Sizer, Dr. Laura Wenk, and Dr. Berna Turam for their valuable contribution in the designing of the survey instrument.

\section{Author details}

1 Department of Sociology, University of California, San Diego, 401 Social Science Building, 9500 Gilman Drive. La Jolla, CA 92093-0533, USA. ² School of Cognitive Science, Hampshire College, Adele Simmons Hall, 893 West Street, Amherst, MA 01002, USA.

Received: 8 January 2013 Accepted: 8 January 2013

Published: 26 March 2013

\section{References}

Allgaier, J. (2010). Scientific experts and the controversy about teaching creation/ evolution in the UK press. Science \& Education, 19(6-8), 797-819.

Asghar, A, \& Alters, B. (2007). Science is in our brains and religion is in our blood: Muslim teachers' and scientists' conceptions of evolutionary science and evolution education. New Orleans, LA: Proceedings, National Association for research in Science Teaching (NARST) Conference.

Blancke, S. (2011). Towards an Integrated Understanding of Creationism in Europe. PhD thesis, Gent University.

BouJaoude, S, Asghar, A, Wiles, JR, Jaber, L, Sarieddine, D, \& Alters, B. (2011a). Biology professors' and teachers' positions regarding biological evolution and evolution education in a Middle Eastern society. International Journal of Science Education, 33(7), 979-1000.

BouJaoude, S, Wiles, JR, Asghar, A, \& Alters, B. (2011b). Muslim Egyptian and Lebanese students' conceptions of biological evolution. Science \& Education, 20(9), 895-915

Brem, SK, Ranney, M \& Schindel, J. (2003). Perceived consequences of evolution: college students perceive negative personal and social impact in evolutionary theory. Science Education, 87(2), 181-206.

Curry, A. (2009). Creationist beliefs persist in Europe. Science, 323(5918), 1159
Downie, JR. (2004). Evolution in health and disease: the role of evolutionary biology in the medical curriculum. BioScience Education, 4. http://www. bioscience.heacademy.ac.uk/journal/vol4/Beej-4-3.pdf.

Edis, T. (2007). An illusion of harmony: science and religion in Islam. Amherst, NY: Prometheus Books.

Enserink, M. (2007). In Europe's mailbag: a glossy attack on evolution. Science, 315 (5814), 925

Evans, J, \& Evans, M. (2010). Arguing against darwinism: religion, science, and public morality. In B Turner (Ed.), The new Blackwell companion to the sociology of religion (pp. 286-308). New York: Blackwell.

Gallup Inc. (2012). Evolution, creationism, intelligent design. Gallup Poll News Service. http://www.gallup.com/poll/21814/evolution-creationism-intelligentdesign.aspx/ Accessed 15 Aug 2012

Geertz, C. (1973). The interpretation of cultures. New York, NY: Basic Books, inc.

Gish, O, \& Godfrey, M. (1979). A reappraisal of the "brain drain"-with special reference to the medical profession. Social Science \& Medicine, 13(1), 1-11.

Hameed, S. (2008). Bracing for Islamic creationism. Science, 322(5908), 1637-1638.

Hassan, R. (2007). On being religious: patterns of religious commitment in Muslim societies. Muslim World, 97(3), 437-478.

Kim, SU, \& Nehm, R. (2011). A cross-cultural comparison of Korean and American science teachers' views of evolution and the nature of science. International Journal of Science Education, 33(2), 197-227.

Kitcher, P. (2008). Science, religion, and democracy. Episteme, 5(1), 5-17.

Knorr, CK. (2007). Culture in global knowledge societies: knowledge cultures and epistemic cultures. Interdisciplinary Science Reviews, 32(4), 1-15.

Koning, D. (2006). Anti-evolutionism among Muslim students. ISIM Review, 18(1), 48-49.

Masci, D. (2009). Public opinion on religion and science in the United States. Pew Forum on Religion and Public Life. http://www.pewforum.org/Science-andBioethics/Public-Opinion-on-Religion-and-Science-in-the-United-States.aspx. Accessed 8/15/2012.

Miller, JD, Scott, EC, \& Okamoto, S. (2006). Public acceptance of evolution. Science, 313(5788), 765-766

Newport, F. (2012). In U.S., 46\% hold creationist view of human origins. Gallup Poll News Service.. http://www.gallup.com/poll/155003/Hold-CreationistView-Human-Origins.aspx. Accessed 15 Aug 2012.

Numbers, RL. (2006). The creationists: from scientific creationism to intelligent design. Cambridge, MA: University Press.

Punjab Textbook Board. (2003). Biology 12. Lahore, Pakistan: Punjab Textbook Board.

Riexinger, M. (2002). The Islamic creationism of Harun Yahya. ISIM Newsletter, $11(2), 5$.

Ruby, R, \& Smith, G. (2007). How Muslims compare with other religious Americans. Pew Forum on Religion and Public Life. http://www.pewforum.org/Muslim/HowMuslims-Compare-With-Other-Religious-Americans.aspx. Accessed 15 Aug 2012.

Rutledge, ML, \& Warden, MA. (1999). Development and validation of the measure of acceptance of the theory of evolution instrument. School Science and Mathematics, 99(1), 13-18.

Shtulman, A. (2006). Qualitative differences between naive and scientific theories of evolution. Cognitive Psychology, 52(2), 170-194.

Southcott, R, \& Downie, JR. (2012). Evolution and religion: attitudes of Scottish bioscience students to the teaching of evolutionary biology. Evolution: Education and Outreach, 5(2), 301-311. doi:10.1007/s12052-012-0419-9.

Tashakkori, A, \& Teddlie, C (Eds.). (2002). Handbook of mixed methods social and behavioral research. Thousand Oaks, CA: Sage Publications.

The Pew Forum on Religion and Public Life. (2008). U.S. religious landscape survey, Washington, D.C: The Pew Research Center.

The Pew Forum on Religion and Public Life. (2012). The world's Muslims: unity and diversity. Washington, D.C: The Pew Research Center.

Yousuf A, Daud M A, Nadeem, A (2011). Awareness and acceptance of evolution and evolutionary medicine among medical students in Pakistan. Evolution: Education and Outreach, 4:580-588. doi:10.1007/s12052-011-0376-8

Zaidi, SA. (1987). Undergraduate medical education in underdeveloped countries: the case of Pakistan. Social Science \& Medicine, 25(8), 911-919.

doi:10.1186/1936-6434-6-2

Cite this article as: Everhart and Hameed: Muslims and evolution: a study of Pakistani physicians in the United States. Evolution: Education and Outreach 2013 6:2. 